\title{
PERSPECTIVA (LEGAL) DE GÉNERO EN EDUCACIÓN
}

\author{
Remedios Álvarez Terán \\ Universidad de La Rioja
}

\begin{abstract}
RESUMEN: La igualdad es un principio político legalmente reconocido en todos los ordenamientos jurídicos de nuestro contexto cultural. Sin embargo, la inercia es una losa y fuente de frustración para millones de mujeres. Mientras las Leyes de nuestras sociedades insisten en que todos y todas somos iguales, la realidad nos demuestra que esto es falso. Todas las estadísticas reflejan machaconamente las diferencias existentes entre mujeres y hombres. El poder político, el jurídico, el económico, el cultural, todos los ámbitos muestran que ni el acceso ni la permanencia se producen en igualdad. No podemos hablar de una cuestión de tiempo, porque hay mujeres preparadas para ocupar paritariamente todos los ámbitos de poder. La Universidad arroja cada año sus estadísticas que confirman, no sólo la igualdad, sino el predominio de las mujeres. Sin embargo, más allá de estos datos, las desigualdades estructurales persisten.
\end{abstract}

Palabras clave: Igualdad, educación, legalidad.

\section{A LEGAL GENDER OVERVIEW IN EDUCATION}

ABSTRACT: The equality is a political legally recognized principle in all legal systems in our cultural context. Nevertheless, the routine is a heavy burden and a source of frustration for millions of women. While the laws in our societies insist on the fact that all men and women are equals, the reality shows that this is false. All the statistics reflect insistently the real differences between women and men. The political, legal, economic, cultural power, all the fields show that nor the coming or the continuance happens on equal terms. And we cannot talk about a question of time any more, because there are qualified women ready to achieve equally all the power fields. The University shows every year its statistics that confirm, not only 
the equality, but also the preponderance of women. Beyond these details, however, structural disparities persist.

Keywords: Equality, education, legality.

\section{Introducción}

Investigamos los pasados porque nos ayudan a comprender los presentes y a evitar los errores que entonces se cometieron. Como historiadoras y como docentes ese es un gran reto. Por eso, cuando reflexionamos sobre el colectivo de las mujeres, más o menos la mitad de cada población en cada tiempo y lugar, observamos que ni en el pasado ni el en presente llegan a obtener la representación social, política, laboral e institucional que les correspondería por su peso demográfico. Es evidente que el mero paso del tiempo no garantiza que las mujeres logren la visibilidad social que les correspondería.

La igualdad entre mujeres y hombres es un principio político legalmente reconocido en todos los ordenamientos jurídicos de nuestro contexto cultural. Sin embargo, la inercia histórica es una losa y una fuente de frustración para millones de mujeres. Las injusticias estructurales persisten. Y, mientras las leyes de de nuestros ordenamientos insisten en que todos y todas somos iguales, la realidad nos demuestra que esto es falso. Todos los indicadores socio demográficos evidencian las diferencias en todos los órdenes, que hay entre mujeres y hombres. Ni el acceso ni la permanencia de mujeres al poder político, al económico y al cultural se producen paritariamente. Y ya no podemos hablar a estas alturas del siglo XXI de una cuestión de tiempo. Los saldos sobre las y los nuevos graduados que cada año arroja la universidad, ponen en evidencia que ni es una cuestión de cifras ni de tiempo. Hay suficientes mujeres y sobradamente preparadas para ocupar las mismas o mayores cotas de poder que los hombres. Sin embargo, más allá de estos datos, la desigualdad persiste.

Desde nuestro punto de vista, como personas, como docentes y como ciudadanas, es moralmente necesario contribuir a despertar una conciencia crítica en el alumnado respecto a la situación real de las mujeres en el mundo. Los pasados deben ser una referencia para entender los presentes, los presentes construyen futuros. Por eso, en estas primeras décadas del siglo XXI resulta inadmisible un estudio riguroso de cualquier ciencia social, sin incorporar el papel, el discurso y las acciones de las mujeres a las ciencias, pero no sólo desde este presente y para el futuro, sino también desde el pasado. Es preciso actualizar los contenidos y releer la historia para comprender la realidad político-social actual de las mujeres y su dificultad para acceder a la ciudadanía como individuas ${ }^{1}$ de pleno derecho. Es necesario contribuir

1. Individua propone Susana Tavera, para deshacer el equívoco (individuos no incluye a las mujeres), para eliminar las connotaciones negativas, para nombrar a las mujeres. En // Curso de Historia de las Mujeres, Fundación Sánchez Albornoz, Ávila, 2007, inédito. 
a reflexionar y a profundizar en un conocimiento histórico global, sin sesgo androcéntrico ${ }^{2}$.

Y además, es necesario fomentar la sensibilidad ante los problemas sociales actuales y potenciar la actitud crítica y el sentido responsable y solidario en la defensa de los derechos humanos, los valores democráticos y el camino hacia la paz y la igualdad.

Es incuestionable que existe una relación de doble recorrido entre igualdad, educación y legislación. Éste es el camino. Educar en y para la igualdad, exigir que las leyes se cumplan es un gran reto. Creo sinceramente, con Simone de Buvoir, que no nacemos mujeres ni hombres, nos hacemos a lo largo de nuestra vidas y merced a los procesos de socialización, entre los que tiene un protagonismo innegable la educación. La feminidad y la masculinidad son constructos culturales que se aprenden y se perpetúan históricamente.

El artículo 14 de la Constitución española proclama el derecho a la igualdad y a la no discriminación por razón de sexo. Por su parte, el artículo 9.2 consagra la obligación de los poderes públicos de promover las condiciones para que la igualdad de las personas, y de las agrupaciones en las que se integra, sean reales y efectivas (transversalidad).

Una sola ley no cambia nada y mucho menos lo hace en un tiempo corto, cambiar la mentalidad puede llevar siglos, pero una ley pone de manifiesto que el contrato que teníamos hasta ahora no nos sirve y que vamos a hacer otro nuevo. Por este motivo, una ley, las leyes suponen un comienzo de cambio y casi siempre un impulso para el mismo.

\section{Fundamentación legal}

\subsection{Tratados internacionales}

La igualdad entre mujeres y hombres es un principio jurídico universalmente reconocido en diversos textos internacionales sobre derechos humanos:

Para hacer balance sobre la situación de las mujeres en el mundo y proponer medidas que ayudaran a erradicar la discriminación, Naciones Unidas se propuso convocar Conferencias Mundiales (Méjico, 1975). En 1979 se aprobó la Convención sobre la eliminación de todas las formas de discriminación contra las mujeres, que España ratificó en 1983. Otras conferencias fueron: Copenhague (1980), Nairobi (1985) y Beijín (1995). En el año 2000 en Nueva York se hizo una revisión de los últimos acuerdos. La última Conferencia, Pekín+10, se celebró también en Nueva York en marzo de 2005. Como consecuencia de esta

2. Androcentrismo: el hombre como medida de todas las cosas. Enfoque que, desde la exclusiva perspectiva masculina, hace extensivos sus conclusiones a la generalidad de las personas: hombres y mujeres. Este enfoque unilateral se ha llevado a cabo sistemáticamente en todas las ciencias. 
última, se elaboró el documento Objetivos de desarrollo del Milenio, que hace hincapié en la necesidad de resolver las desigualdades económicas y culturales que lastran a nivel mundial el avance de las mujeres ${ }^{3}$.

En el plano de la educación, la Declaración de Bolonia, suscrita por los ministros de educación de 29 países europeos reunidos en junio de 1999, marcó el inicio oficial del proceso de convergencia hacia un espacio común europeo de educación superior que culminó en $2010^{4}$.

El Tratado de Ámsterdam, el 1 de mayo de 1999, reconocía que, la igualdad entre mujeres y hombres era un objetivo que debería integrarse en todas las políticas y acciones de la Unión Europea (tranversalidad) y de sus miembros integrantes.

La declaración de Berlín en 2003, reconocía que, era imprescindible introducir la perspectiva de género en el terreno educativo como corriente principal del diseño de los programas, los sistemas de evaluación y las estructuras académicas, para garantizar que la enseñanza superior podría responder a la necesidad de formar en los nuevos perfiles profesionales.

\subsection{Legislación española}

La Ley Orgánica 1/1990, de Ordenación General del Sistema Educativo (LOGSE), estableció el principio de la no discriminación por razón de sexo. Fue la primera vez que una norma educativa recogía, en nuestro país, una declaración de principios de esta índole:

La educación permite, en fin, avanzar en la lucha contra la discriminación y la desigualdad, sean éstas por razón de nacimiento, raza, sexo, religión u opinión, tengan un origen familiar o social, se arrastren tradicionalmente o aparezcan continuamente con la dinámica de la sociedad $^{5}$.

La Ley Orgánica de Educación 2/2006 (LOE), en su Título Preliminar, define los Principios y fines que la guían y persigue. Entre ellos, el desarrollo de la igualdad de derechos y oportunidades y el fomento de la igualdad efectiva

3. Objetivos de desarrollo del Milenio. Informe 2008, Naciones Unidas, <http://www. un.org/spanish/millenniumgoals/pdf/MDG_Report_2008_SPANISH.pdf> [28/02/09].

4. Precedida de tres manifiestos europeos en relación con la institución universitaria: La Carta Magna de las Universidades Europeas, Bolonia 1988. La Declaración de la Sorbona, Mayo de 1998, firmada por los ministros de Educación de Francia, Alemania, Italia y el Reino Unido. Finalmente, la Declaración de Bolonia, firmada en Junio de 1999 por una treintena de Ministros Europeos de Educación, en aras de una mejor apertura y homogeneización de las universidades europeas a través de un Área Europea de Educación Superior. Documentos sobre el Espacio europeo de educación, <http//:eee.universia.es> [28/08/2006].

5. Ley Orgánica General del Sistema Educativo (LOGSE), de 3 de octubre de 1990. Preámbulo. Posteriormente insiste en el Artículo 2.3.c. 
entre hombres y mujeres; la educación en el respeto de los derechos y libertades fundamentales, en la igualdad de derechos y oportunidades entre hombres y mujeres y en la igualdad de trato y no discriminación de las personas con discapacidad. Pero no se queda ahí, sino que, insiste en que estos principios sean tenidos en cuenta en cada etapa del sistema. Así, la Educación Primaria contribuirá a desarrollar en los niños y niñas las capacidades que les permitan conocer, comprender y respetar las diferentes culturas y las diferencias entre las personas, la igualdad de derechos y oportunidades de hombres y mujeres y la no discriminación de personas con discapacidad. En relación con la Educación Secundaria Obligatoria, señala que se deberá valorar y respetar la diferencia de sexos y la igualdad de derechos y oportunidades entre ellos, así como, rechazar los estereotipos que supongan discriminación entre hombres y mujeres y fortalecer sus capacidades afectivas en todos los ámbitos de la personalidad y en sus relaciones con los demás; también la educación debe proponerse en esta etapa, rechazar la violencia, los prejuicios de cualquier tipo, los comportamientos sexistas y enseñar a resolver pacíficamente los conflictos. Con respecto a las enseñanzas postobligatorias, señala la ley que en el Bachillerato, se deberá fomentar la igualdad efectiva de derechos y oportunidades entre hombres y mujeres, analizar y valorar críticamente las desigualdades existentes e impulsar la igualdad real y la no discriminación de las personas con discapacidad. Mientras que en la Formación Profesional, el alumnado deberá aprender por sí mismo y trabajar en equipo, así como, formarse en la prevención de conflictos y en la resolución pacífica de los mismos en todos los ámbitos de la vida personal, familiar y social, sin perder de vista que, se debe fomentar la igualdad efectiva de oportunidades entre hombres y mujeres para que puedan acceder a una formación que permita todo tipo de opciones profesionales y el ejercicio de las mismas. Al referirse a la Educación de Personas Adultas, la Ley se plantea los siguientes objetivos: enseñar a prever y resolver pacíficamente los conflictos personales, familiares y sociales; fomentar la igualdad efectiva de derechos y oportunidades entre hombres y mujeres, así como, analizar y valorar críticamente las desigualdades que pueden existir entre ellos y en la sociedad $^{6}$.

Pero la educación no sólo se efectúa en el ámbito académico, las personas se forman en todos los ambientes en los que se socializan. Por eso, las leyes, deben incidir en otros aspectos de la realidad. Existen, pues, otras disposiciones que urgen a las administraciones a tomar medidas transversales que impidan las desigualdades de género y a que contribuyan a romper con todo tipo de discriminaciones.

6. Ley Orgánica de Educación, 2/2006, de 3 de mayo. Artículo 1. Principios. Artículo 2. Fines. Capítulo II, Educación primaria. Artículo 17. Objetivos de la educación primaria. Capítulo III, Educación secundaria obligatoria, Artículo 23. Objetivos, Capítulo IV, Bachillerato, Artículo 33. Objetivos. Capítulo V, Formación profesional. Artículo 40. Objetivos. Capítulo IX, Educación de personas adultas. Artículo 66. Objetivos y principios. 
La primera, desde un punto de vista cronológico, es la Ley Orgánica 1/2004 de Medidas de Protección Integral contra la Violencia de Género. El texto consta de 78 artículos. De ellos, cinco adquieren especial relevancia en relación con la educación. Ya en su Exposición de motivos III, anuncia que en la Educación Secundaria se incorpora una materia sobre la igualdad entre hombres y mujeres y contra la violencia de género como contenido curricular, y que, además, en todos los Consejos Escolares debe haber una persona que se ocupe de impulsar medidas educativas en favor de la igualdad y contra la violencia hacia las mujeres. También señala la necesidad de que la publicidad respete la dignidad de las mujeres y su derecho a una imagen no estereotipada ni discriminatoria, tanto si se exhibe en los medios de comunicación públicos como en los privados. Siete años después, si en el aspecto educativo se están cumpliendo los mandatos de esta norma, con la publicidad, parece que, la batalla está perdida.

El Título I de la Ley 1/2004, "Principios y valores del sistema educativo", incide, en el artículo 4, en la igualdad entre mujeres y hombres como valor fundamental y en la necesidad de integrarlo en cada uno de los escalones del recorrido académico que va de la Educación Infantil a la Universidad: "Las Universidades incluirán y fomentarán en todos los ámbitos académicos la formación, docencia e investigación en igualdad de género y no discriminación de forma transversal"7. Además en relación con la Educación Superior, las administraciones públicas competentes fomentarán la enseñanza y la investigación sobre el significado y alcance de la igualdad entre mujeres y hombres. En particular y con tal finalidad promoverán la inclusión en los planes de estudio que proceda de contenidos en materia de igualdad entre mujeres y hombres, la creación de postgrados específicos y la realización de estudios e investigaciones especializadas en la materia. El artículo 7 por su parte repara en la necesidad de que en la formación del profesorado, tanto inicial como en la permanente, se incluya una preparación específica en materia de igualdad, con el fin de asegurar que se adquieren los conocimientos y técnicas que habiliten para impartir una educación en igualdad y no sexista.

La Ley $1 / 2004$, en su artículo 28, también se pronuncia sobre la Sociedad de la Información y señala que todos los programas públicos de desarrollo deberían incorporar la efectiva consideración del principio de igualdad de oportunidades entre mujeres y hombres en su diseño y ejecución. Así, el Gobierno tendría que promover la plena incorporación de las mujeres en la Sociedad de la Información mediante el desarrollo de programas específicos, en especial, en materia de acceso y formación en tecnologías de la información y de las comunicaciones, contemplando las de colectivos de riesgo de exclusión y del ámbito rural. Y además debería promover los contenidos creados por mujeres

7. Ley Orgánica 1/2004, de Medidas de Protección Integral contra la Violencia de Género. BOE 29 de diciembre de 2004. Capítulo I, artículo 4. <http://noticias.juridicas.com/base_ datos/Admin/lo1-2004.t1.html\#c1> [05/09/2006]. 
en el ámbito de la Sociedad de la Información. Y no perder de vista que, se debería garantizar que lenguaje y contenidos de los proyectos del ámbito de las tecnologías de la información y de la comunicación, sufragados total o parcialmente con dinero público, no sean sexistas.

La publicidad constituye un elemento culturizador de primer orden. Para la Ley $1 / 2004$ no pasa desapercibido el pernicioso efecto de muchos de sus contenidos sexistas. El artículo 10 señala que se considera ilícita la publicidad que utilice la imagen de las mujeres con carácter vejatorio o discriminatorio. Y que se concreta (Disposición adicional sexta) en la que atenta contra la dignidad de las personas o vulnera los valores y derechos reconocidos en la Constitución, especialmente a los referidos en los artículos 18 y 20, apartado 4. O sea, los anuncios que presentan a las mujeres utilizando particular y directamente su cuerpo o partes del mismo como mero objeto desvinculado del producto que se pretende promocionar o bien su imagen asociada a comportamientos estereotipados. Es decir, casi toda la publicidad.

En su artículo 11, señala que el Ente público responsable de velar por la igualdad en los medios audiovisuales debe actuar en consecuencia ante los mensajes ilícitos, sin perjuicio de las posibles actuaciones por parte de otras entidades.

Según el artículo 36 de la Ley 1/2004, los medios de comunicación de titularidad pública tendrían que velar por la transmisión de una imagen igualitaria, plural y no estereotipada de mujeres y hombres en la sociedad y promover el conocimiento y la difusión del principio de igualdad entre mujeres y hombres.

Finalmente, en la Disposición adicional sexta, el texto otorga explícitamente a los medios de comunicación un papel educador, por eso la publicidad o la televenta dirigidas a menores deberán transmitir, en cualquier caso, una imagen igualitaria, plural y no estereotipada de mujeres y hombres.

Parece muy evidente que estas disposiciones y diligencias no se cumplen en su totalidad. La Publicidad sigue siendo un soporte de discursos de desigualdad y discriminación para las mujeres, totalmente aceptado e incorporado a nuestra cotidianidad. Este mecanismo contribuye a propagar un reparto de papeles muy sexista y agresivo. Se difunde el discurso políticamente correcto sobre la igualdad en las aulas y en las leyes, sin embargo, cada día la televisión, la prensa escrita, las revistas de entretenimiento, los cómics y las vallas publicitarias nos muestran esquizofrénicamente no hay sino desigualdad. Los torsos y/o los glúteos de mujeres jóvenes y muy jóvenes, incluso desprovistas de sus cabezas, en ocasiones, se utilizan para vender cualquier producto. Esto por no mencionar las machaconas campañas cosméticas y de corrección quirúrgica que se diseñan exclusivamente para el consumo de mujeres y que lanzan el mensaje de la necesaria juventud, belleza y perfección exigibles a los cuerpos femeninos ${ }^{8}$. La publicidad es muy

8. "La discriminación invisible", El País, <http://www.elpais.es/articuloCompleto/opinion/ discriminacion/invisible/elpepiopi/20061110elpe piopi_5/Tes/EL PAíS> [10-11-2006]. 
conservadora, muy reaccionaria y muy machista. Las imágenes de mujeres aparecen en una proporción mucho mayor que las de hombres y sirven para promocionar casi todo, tenga que ver o no con los y las hipotéticas compradoras. Los mecanismos correctores no funcionan.

La Orden de 4 de marzo de 2005 es otra de las normas transversales para favorecer la igualdad entre mujeres y hombres. En el apartado 4, dedicado a la Investigación, se acuerda crear una unidad específica denominada "Mujer y Ciencia" y que aborde la situación de las mujeres en las instituciones investigadoras y mejore su presencia en las mismas. Y, también, se decide incluir, como criterio adicional de valoración en la concesión de ayudas a proyectos de investigación, la participación de mujeres en los equipos de trabajo ${ }^{9}$.

Una tercera disposición, que incide en la necesidad de instaurar medidas que rompan con las desigualdades, es la Ley Orgánica 3/2007 para la igualdad efectiva de mujeres y hombres ${ }^{10}$. Ya en el Capítulo II, señala que el sistema educativo debe incluir entre sus fines la educación en la igualdad de derechos y oportunidades entre mujeres y hombres y debe además incluir, dentro de sus principios de calidad, la eliminación de los obstáculos que dificultan la igualdad efectiva entre mujeres y rechazar los estereotipos que supongan la discriminación entre unas y otros. El artículo 24 insiste en la necesidad de integrar el principio de igualdad en las políticas de educación y garantizar un igual derecho a la educación de mujeres y hombres a través de la integración activa, en los objetivos y en las actuaciones educativas, del principio de igualdad de trato, evitando que por comportamientos sexistas o por los estereotipos sociales asociados se produzcan desigualdades de género. Señala que, en el ámbito de sus respectivas competencias, las administraciones públicas desarrollarán las siguientes actuaciones: la atención especial en los currículos y en todas las etapas educativas al principio de igualdad entre mujeres y hombres y la eliminación y el rechazo de los comportamientos y contenidos sexistas y estereotipos que supongan discriminación de género, con especial consideración a ello en los libros de texto y en los materiales educativos. Y, finalmente, la integración del estudio y aplicación del principio de igualdad en los cursos y programas para la formación inicial y permanente del profesorado ${ }^{11}$.

El Título II de la Ley 3/2007, denominado "Acción administrativa para la igualdad", establece las pautas generales de actuación de los poderes públicos

Sebastián, Julia, "La imagen de la mujer en la publicidad: Análisis de los mensajes latentes en los anuncios de contenido sexual", en Ortega, Margarita, Sebastián, Julia y Torre, Isabel de la (eds.), Las mujeres en la opinión pública: X Jornadas de Investigación Interdisciplinaria sobre la mujer, Madrid, Instituto Universitario de Estudios de la Mujer, Universidad Autónoma de Madrid, 1995, pp. 121-128.

9. Orden de 4 de marzo de 2005 sobre Medidas para favorecer la Igualdad entre hombres y mujeres. <http://www.la-moncloa.es/ConsejodeMinistros/Referencias/_2005/c0403050. htm\#lgualdad> [04/10/2006].

10. Ley Orgánica 3/2007, de 22 de marzo, para la igualdad efectiva de mujeres y hombres.

11. Ibidem, Artículo 24. Integración del principio de igualdad en la política de educación. 
en relación con la igualdad. La norma define el principio de transversalidad y los instrumentos para su integración en la elaboración, ejecución y aplicación de las normas. A partir de su implantación, las administraciones públicas lo integrarán, de forma activa, en la adopción y ejecución de sus disposiciones normativas, en la definición y presupuestación de políticas públicas en todos los ámbitos y en el desarrollo del conjunto de todas sus actividades. El Título VIII establece la creación de una Comisión Interministerial de Igualdad entre Mujeres y Hombres y de las Unidades de Igualdad en cada Ministerio. Además, se constituye un Consejo de participación de las mujeres, como órgano colegiado, que debería servir de cauce para la participación institucional en estas materias.

\section{Conclusiones}

El género es un elemento constitutivo de las relaciones sociales, basado en las diferencias biológicas que distinguen a los sexos $y$, a su vez, el género es una forma primaria de relaciones significantes de $\operatorname{poder}^{12}$. $\mathrm{Y}$, sin embargo, no nacemos mujeres ni hombres, nos hacemos a lo largo de nuestra vida y merced a los procesos de socialización entre los que tienen un protagonismo innegable la educación. La especie humana es una sola y, salvo sus actos, nada hace a una persona mejor que otra, no existe, en nuestra opinión, una naturaleza masculina racional y dominadora ni una femenina frágil, sumisa e irracional.

La igualdad entre mujeres y hombres, una necesidad secularmente sentida, no va a llegar por sí sola, sino que necesita de un esfuerzo grande y especial por parte de toda la sociedad. Por eso, educar en igualdad y para la igualdad no es tarea de unos pocos, sino responsabilidad de toda la sociedad. La actitud del profesorado y los comportamientos y las relaciones que se establecen con el alumnado constituyen modelos que perpetúan ideologías. También la familia y toda la sociedad deben implicarse en este objetivo.

La igualdad no es una cuestión sólo de mujeres y para las mujeres. Sino que involucra a todos los individuos y supone un rasgo de modernización de un país. La práctica democrática extendida a toda la ciudadanía legitima a esa sociedad, mientras que las carencias la desautorizan. La infrarrepresentación de las mujeres, cualquiera que sea el ámbito, debe plantearse como un déficit de democracia. La superación de este déficit mediante la representación paritaria forma parte de la propuesta de un nuevo contrato social para el siglo XXI. Se trata de lograr un modelo de sociedad más justa, donde las responsabilidades tanto públicas como familiares o privadas estén repartidas entre hombres y mujeres, donde las personas tengamos derechos porque formamos parte de la ciudadanía, independientemente de nuestro sexo, origen, cultura,

12. Scott, Joan W., "El eco de la fantasía: la historia y la construcción de la identidad", Ayer, 62 (2006), pp. 111-138. 
orientación sexual o nivel económico. Se entiende la paridad como una representación equilibrada de hombres y mujeres, de forma que ninguno de los dos sexos tenga una presencia mayor al $60 \%$ ni menor al $40 \%$.

España ha cambiado mucho en todos los aspectos en 40 años, por ejemplo, el acceso a la educación se ha universalizado, para todas las personas. Históricamente, algunas modificaciones se producen cuando hay alfabetización de más de un $30 \%$ de la población femenina, sólo así pueden producirse cambios en las mentalidades (no siempre irreversibles). Por eso, algunos gobiernos inmovilistas tienen buen cuidado de no alfabetizar a las niñas. La educación de las mujeres es siempre un motor del cambio social, educación y ciudadanía, derechos y acceso al poder van de la mano. Si bien es cierto que, atribuir sólo a la educación toda la responsabilidad es exagerado, también es necesario el apoyo de las leyes.

$\mathrm{Ni}$ el Renacimiento ni la llustración ni las Revoluciones Liberales mejoraron la situación de las mujeres como tales. Sabemos que no siempre el tiempo juega a favor de la igualdad. Hay movimientos involucionistas que no aceptan los valores occidentales en relación con las mujeres. La globalización nos devuelve cada día las imágenes de la pobreza y la violencia reflejadas en rostros de mujeres. Algunos estados, incluso de nuestro entorno próximo, proponen un doble tipo de ciudadanía: una de primera para los varones y otra de segunda, para las mujeres ${ }^{13}$.

También en nuestro contexto, la preeminencia de valores androcéntricos sigue incidiendo en todos los ámbitos, la docencia y la investigación no son una excepción. Y esta actitud produce una cierta violencia simbólica. Los estudios de mujeres y sobre mujeres se siguen viendo con cierta conmiseración. Lo que implica que, a pesar de que el corpus de conocimiento está sobradamente asentado y cualificado, no repercute en la docencia ni en la sociedad. Los sistemas de transferencia no funcionan, investigar y enseñar en este caso no van de la mano. La Universidad es una institución de largo recorrido y tiene la obligación de alimentar los valores que consideramos imprescindibles para nuestra convivencia. Debe seguir alentando utopías, alertando conciencias y difundiendo valores justos. Ninguna sociedad moderna, en la que una parte de su ciudadanía no pueda ver reconocidos y ejercer sus derechos, puede considerarse una auténtica democracia. Ninguna democracia será legítima mientras no garantice la igualdad a la mitad de las poblaciones.

Las mujeres, en este tiempo presente, lo recordamos y reivindicamos, docentes, madres, todas ciudadanas y todas personas, cada una debe cumplir su cometido, cada una debe asumir sus responsabilidades. También los hombres tienen su papel, también todos ciudadanos. La igualdad de género nunca hubiera llegado sólo por la lucha de las mujeres, la asunción de este valor por

13. "Ellas", El País, 28/10/97, <http://www.elpais.es/> [10-10-2009]. El sistema sanitario de Afganistán se está hundiendo, como antes se hundió el educativo. 
parte muchos hombres, su participación y su corresponsabilidad, nos viene permitiendo avanzar.

\section{Fuentes}

\subsection{Bibliografía}

BEAUVOIR, Simone de, El segundo sexo. Madrid, 2000.

FERNÁNDEZ VALENCIA, Antonia, "La construcción de la identidad desde la perspectiva de género". Didáctica de las ciencias sociales, geografía e historia, 47 (2006), pp. 33-43.

- "Las mujeres como sujeto histórico: género y enseñanza de la historia". Didáctica de las ciencias experimentales y sociales, 18 (2004), pp. 5-24.

"Ellas", El País, 28/10/97, <http://www.elpais.es/> [10-10-09].

"La discriminación invisible", El País, 20/11/06, <http://www.elpais.es/> [1011-06].

Objetivos de desarrollo del Milenio. Informe 2008, Naciones Unidas, <http:// www.un.org/spanish/millenniumgoals/pdf/MDG_Report_2008_SPANISH. pdf> [28-02-09].

SAU, Victoria, Un diccionario ideológico feminista. Barcelona, 1990.

SEBASTIÁN, Julia, "La imagen de la mujer en la publicidad: Análisis de los mensajes latentes en los anuncios de contenido sexual", en Ortega, Margarita, Sebastián, Julia y Torre, Isabel de la (eds.), Las mujeres en la opinión pública: X Jornadas de Investigación Interdisciplinaria sobre la mujer, Madrid, Instituto Universitario de Estudios de la Mujer, Universidad Autónoma de Madrid, 1995, pp. 121-128.

SCOTT, Joan, "El género: una categoría útil para el análisis histórico". Amelang, J. S. y Nash, Mary. Historia y género: las mujeres en la Europa Moderna y Contemporánea. Valencia, 1990, pp. 23-56.

-, "El eco de la fantasía: la historia y la construcción de la identidad". Ayer 62 (2006), pp. 111-138.

TAVERA, Susana, "Mujeres en la contemporaneidad", I/ Curso de Historia de las Mujeres. Ávila, 2007, inédito.

\subsection{Textos legislativos}

Declaración Universal de Derechos Humanos.

Constitución española de 1978.

Ley Orgánica 11/1983, de 25 de agosto, de Reforma Universitaria.

La Ley Orgánica General del Sistema Educativo (LOGSE), de 3 de octubre de 1990. 
Ley Orgánica 1/2004, de 28 de diciembre, de Medidas de Protección Integral contra la Violencia de Género.

Orden de 4 de marzo de 2005 sobre Medidas para favorecer la Igualdad entre hombres y mujeres.

Ley Orgánica de Educación, 2/2006, de 3 de mayo.

Ley Orgánica 3/2007, de 22 de marzo, para la Igualdad Efectiva de Mujeres y Hombres. 